\title{
Sibelius as a Tool to Improve Student's Ability of Making Counterpoint Melody
}

\author{
Oriana Tio Parahita Nainggolan ${ }^{1}$, Ayu Niza Machfazia ${ }^{2}$, \\ Fortunata Tyasrinestu ${ }^{1,4}$, Djohan $^{3}$ \\ and Phakkharawat Sittiprapaporn ${ }^{5, *}$
}

\footnotetext{
${ }^{1}$ Department of Music Education, Faculty of Performing Arts, Indonesia Institute of the Arts, Yogyakarta, Indonesia

${ }^{2}$ Department of Music Education, Faculty of Languages and Arts, Yogyakarta State University, Yogyakarta, Indonesia

${ }^{3}$ Department of Performing Arts, Faculty of Performing Arts, Indonesia Institute of the Arts, Yogyakarta, Indonesia

${ }^{4}$ Graduate School of the Indonesia Institute of the Arts, Yogyakarta, Indonesia

${ }^{5}$ Neuropsychological Research Laboratory, Department of Anti-Aging and

Regenerative Science, School of Anti-Aging and Regenerative Medicine, Mae Fah Luang University, Bangkok, Thailand

E-mail: orianatioparahitangl@gmail.com; ayu@uny.ac.id; tyasrin2@yahoo.com; djohan.djohan@yahoo.com; wichian.sit@mfu.ac.th

${ }^{*}$ Corresponding Author
}

Received 18 August 2020; Accepted 20 July 2021;

Publication 06 November 2021

\section{Abstract}

As a subject for music students, counterpoint contributes to the ability to create a melody. The melody in counterpoint usually consists of two or more layers. In order to make a counterpoint melody, students must acknowledge the rules to construct the counterpoint melody. A good counterpoint melody involves two important things: the flow of the melody in a vertical and horizontal in vertical line (interval) and the musical texture of the melody. As a beginner in learning counterpoint, writing a counterpoint melody might be difficult at first. Learning counterpoint investigation was found that students

Journal of Web Engineering, Vol. 20_8, 2361-2390.

doi: 10.13052/jwe1540-9589.2087

(C) 2021 River Publishers 
spent a lot of their time following the counterpoint rules. They particularly did not focus on the musical sense of the counterpoint melody causing the melody loses its musical senses. Sibelius was used here as a tool to solve the problem. Sibelius is a music software which commonly used in writing musical scores. This study examined Sibelius in making a counterpoint melody in learning counterpoint. The data were gathered through observation and interviews with students during learning counterpoint course. The result showed that by using Sibelius, making counterpoint melody more efficient, and it helped student not only focused on the counterpoint rules but also the musical senses of the counterpoint melody. Furthermore, students also showed the improvement of their skills in making a counterpoint melody.

Keywords: Sibelius, counterpoint melody, music, student's ability.

\section{Introduction}

Utilizing Sibelius in making a two-part invention in counterpoint is essential for music hypothesis [1]. The terms of counterpoint got from Latin "punctus contra punctum" or "note against note" [2]. The emphasis word here is on "against". The counterpoint is an art writing composed of a blend of at least two voices (layers). The counterpoint melodies are played or sung 'against', not with one another so the subsequent sounds like a 'conflict'. The conflict isn't in the rough sense. It is all the more almost that at least two lines, with every characteristic, working simultaneously with a typical artistic purpose moving together [3]. There are three materials utilized in counterpoint melodic development including (a) vertical movement; (b) horizontal movement, and (c) musical textures, respectively [4]. The vertical movement alludes to the movement between the upper and lower note (chord or harmony). Horizontal movement is the movement of the melodic line (melodic shape or melodic contour) [5]. Musical texture alludes to the quantities of melodic layers and how these layers identified with one another. As referenced over the counterpoint tune comprises of at least two voices, the musical texture is a significant thought to keep all musical layers associated with one another, or in other words, counterpoint also called the art of consolidating songs [6].

All students at the Music Department, Indonesia Institute of the Arts in Yogyakarta, Indonesia, must take the counterpoint as a required course. This subject is being instructed in two consecutive semesters. The learning content of the principal semester is focused on the introduction of counterpoint; e.g., 
general principles of counterpoint, and executing the overall guidelines in exercises. While in the subsequent semester, the learning content is accentuated on making two voices invention named the two-parts counterpoint tunes or notable as a two-part invention. It begins on making 8 bars of a two-parts invention and toward the end of the semester, students connected with composing 32 up to 64 bars. In Music Department, Indonesia Institute of the Arts Yogyakarta, Indonesia, the counterpoint is educated by lecturing and workshop method. The lecturer clarify learning materials, and from that point onward, the lecture give activities to the students. The lecturer guide and help the students in doing exercises. These exercises are given to the students to pick up the skills in making a counterpoint melody. Students do the exercises physically by composing the contrapuntal tune on a piece of stave paper. They build counterpoint tunes as indicated by the rules offered, attempt to tune in to the melody aurally, assess the tune, and making corrections if there is an error.

Our preliminary observation found that there were several obstacles in learning counterpoint especially in the second semester, which emphasized making two-part inventions. Those obstacles included (a) students wrote their melody manually on pieces of paper, and it wasted their time, (b) students did not have time to practice making counterpoint melody. In order to get more skilful in making a counterpoint melody, they should spare their time in doing a variety of exercises. So, it is very important to allot the time in learning counterpoint, the more exercises they did, the more skill they got, (c) based on the evaluation that gathered from student's assignment, it was found that the counterpoint melody that they made loses the musical textures, and its effect the melody loses their melodic senses. As making a counterpoint melody means making music, the counterpoint melody must have a good musical sense. To help the students solving the problem of making a counterpoint melody, we could use technology as a learning tool. It was used to provide effectiveness and efficiency so that students would easily absorb learning materials. One of the technologies that commonly use in music learning is Sibelius. Composers, arrangers, performers, publishers, professors and students use it to write classical, jazz and vocal music, as well as cinema and television scores. Nowadays computer music notation application most used by music educators because it helps both the teacher and the students doing many things such as writing the music score, composing music, arranging music, and so on, as Watson stated that because they can help music educators and students in so many ways, music notation on a computer software is frequently music technology's original and most widely used sector is usually 
computer program for music notation. In this digital age, web programs (NoreFlight) and music notation programs (including Finale and Sibelius) are web-based program that may be used for a wide range of tasks such as creating and editing worksheets as well as warm-ups, tests and quizzes. It can also be used to create in print or multimedia presentations, and musical figures [7].

As a music notation application, Sibelius also has several educational features previously mentioned by Watson which give the benefit for students. In learning counterpoint, Sibelius help students not only to write counterpoint melody but also at same time they listen to their counterpoint melody. It will be easier for students when they make a counterpoint melody while listening to it $[7,8]$. This process will save their time and they can doing other exercises on making counterpoint melodies. The process of making counterpoint manually (writing on stave paper) took longer time because students will take several steps such as writing the counterpoint melody, playing the written melody on music instrument such as keyboard or piano, revising if there is a melody that does not comply with the counterpoint rules, playing the melody that is written back until the counterpoint melody is made in accordance with the counterpoint rules. By using Sibelius, students go through in making counterpoint melodies on the stave paper will be trimmed and shortened. Besides that, students are also familiar with the features in Sibelius so they can easily use them. Therefore, we examined how Sibelius could be used in making two-part inventions in learning counterpoint.

\section{Research Methods}

This study was conducted with students of the Music Department, Indonesia Institute of Art Yogyakarta, Indonesia whose enrolled counterpoint course. In each meeting of the counterpoint study, the observations made about the use of Sibelius on creating a counterpoint melody given by lecturers. Upon completing the exercise, the students were interviewed about their experiences using Sibelius to create a counterpoint melody. The observations and interviews gave an actual picture of how Sibelius could be a tool for students in creating counterpoint melodies.

\subsection{Participants}

About 36 students took involved in this study. All of the participants were from the Music Department, Indonesia Institute of the Arts Yogyakarta, 


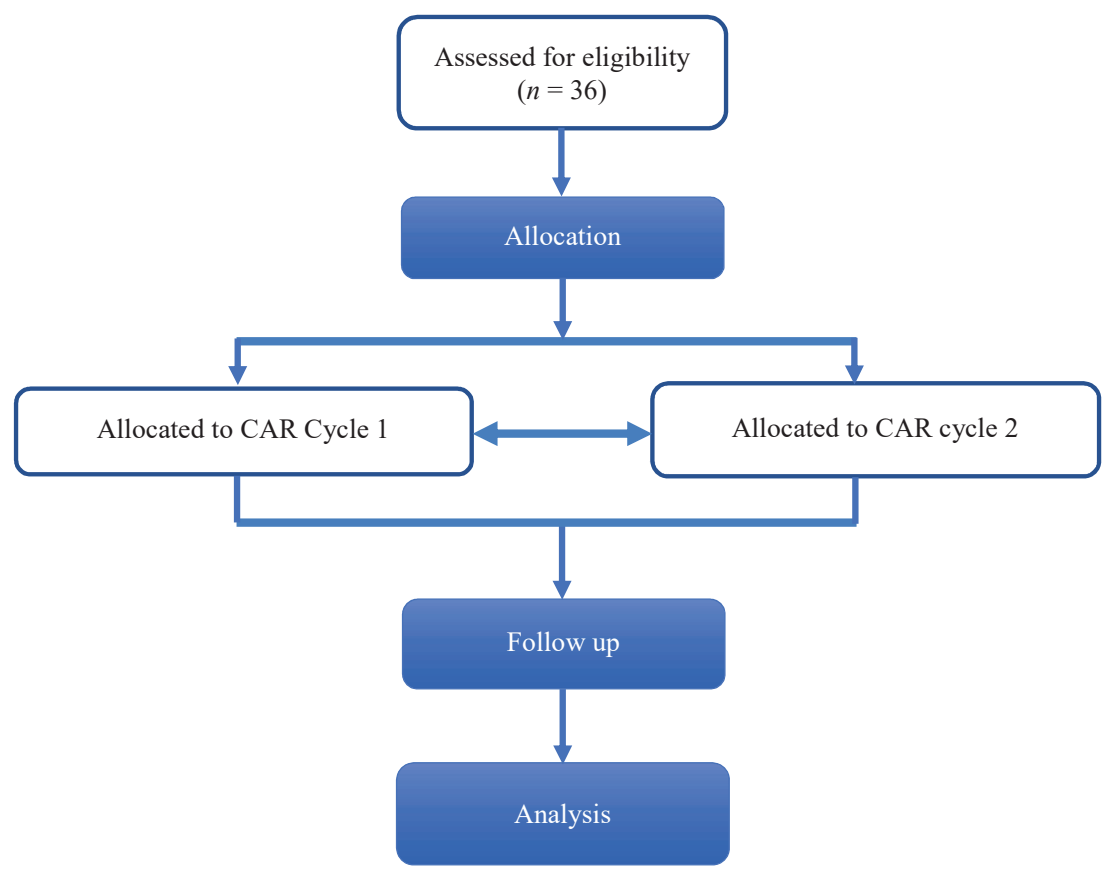

Figure 1 The allocation and follow chart.

Indonesia. All data were obtained from observation during the learning of counterpoint, students learning outcomes, and questionnaire, respectively. The experiment received approval from the committee at the Music Department, Indonesia Institute of the Arts Yogyakarta, Indonesia. Informed consent forms were obtained from all participants. The study protocol is illustrated in Figure 1.

\subsection{Research Design}

Classroom action research (CAR) was applied in this study. It aimed to overcome the problems in the classroom and to increase the quality of learning. In this study, CAR was used to describe the use of Sibelius in making a counterpoint melody. It was expected that the use of Sibelius in making counterpoint melody would make learning more effective. There were four steps in CAR including plan, act, observe, and reflect, respectively. The cyclical nature of typical action research by mean of CAR model [9] in this study is shown in Figure 2. 


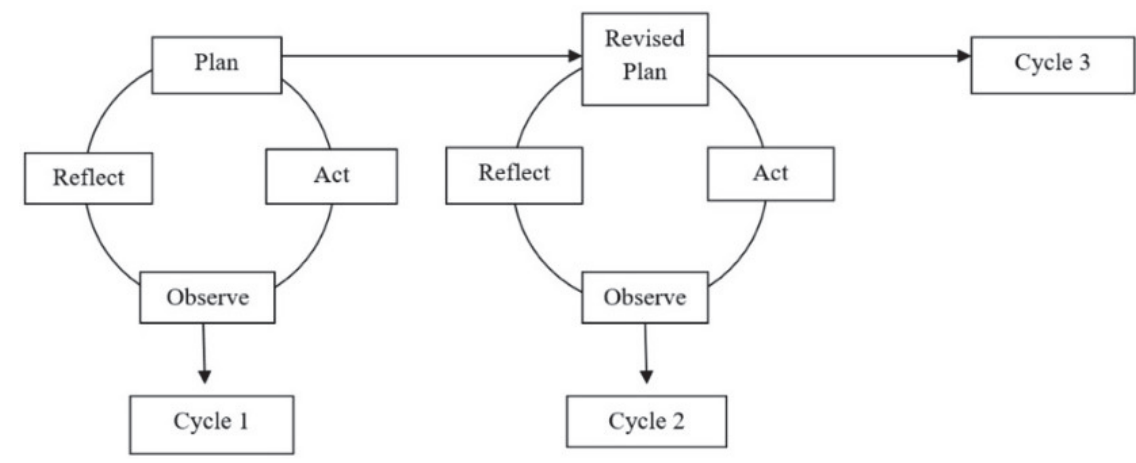

Figure 2 Classroom Action Research (CAR) model of the cyclical nature of typical action research [9] applied in this study.

Moreover, we applied five stages designed by Susman [10] in this study. In giving the elaboration of the simple action research model, Susman distinguishes five stages in conducting each research cycle including (a) diagnosis the problem, (b) action planning, (c) taking action, (d) evaluating, and (e) specifying learning, respectively, as shown in Figure 3.

\subsection{Procedures}

Following the cyclical nature of action research (Figure 2), this study was conducted in several phases as follows:

(1) Planning: In this first step, we identified the problem in learning counterpoint at Music Department, Indonesia Institute of the Arts Yogyakarta, Indonesia, in making a two-part invention. Three problems found in learning counterpoints such as students spent a lot of time in making two-part invention by writing on a paper and its causes students did not have enough time to practice, and most of the student did not pay attention to the musical texture of their counterpoint melody. To solve the student's problem in learning counterpoint, we reviewed related previous studies which had similar issues and then designed a learning scenario by using Sibelius when making two-part invention.

(2) Action: The action here means a corrective action. We provided students with exercises in making two-part invention. Students did their work on their laptops by using Sibelius. The exercises started from 8 bars up to 32 bars in length. We assisted the students while they were working on two-part invention. 


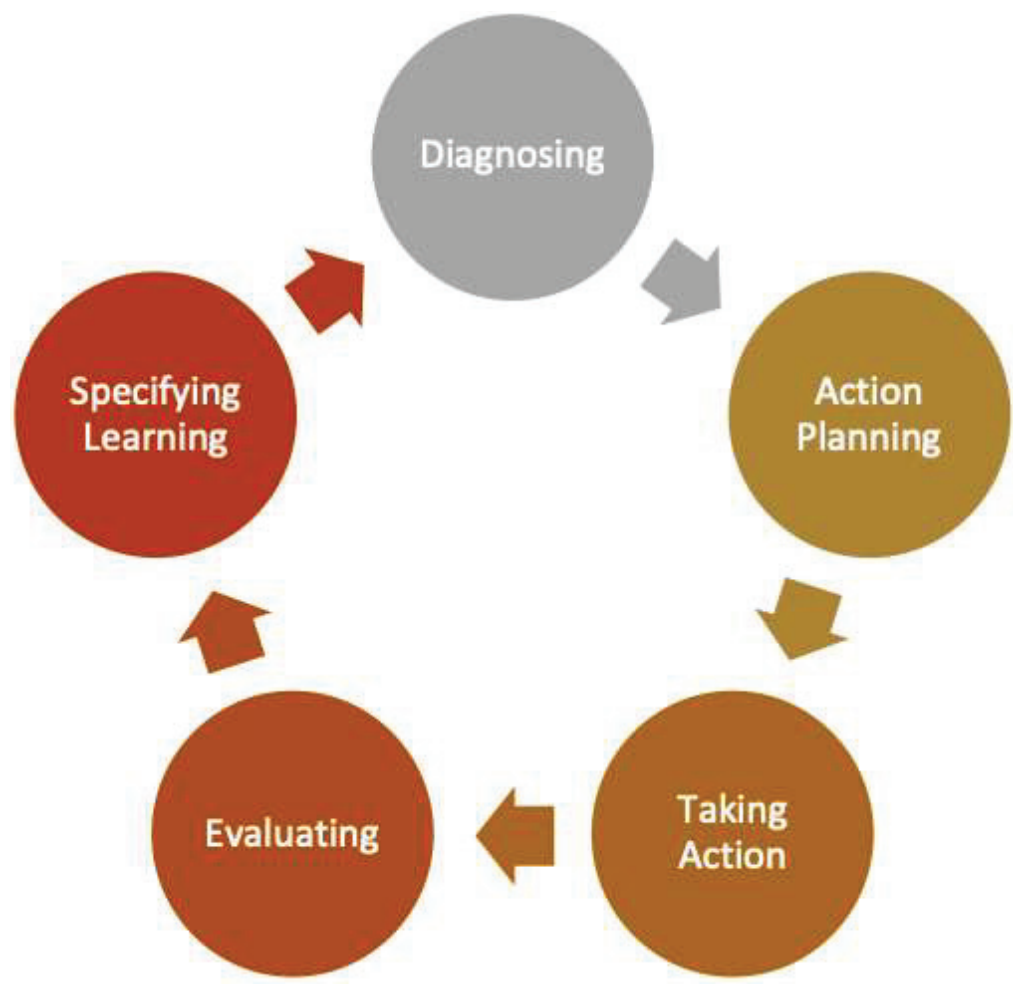

Figure 3 Five stages as action research process in conducting each research cycle including (a) diagnosis the problem, (b) action planning, (c) taking action, (d) evaluating, and (e) specifying learning, respectively [10].

(3) Observe: After students were fluent to work on counterpoint with Sibelius, the instructor gave an assignment that was used to evaluate learning outcomes using Sibelius. The instructor observed and scored the student's work. If the results of student work had not reached expectations of the learning goal, the teacher would give the assignment again to the students until the student fulfilled the learning goal. In this study, the score of student's assignments was used as primary data. The score of student assignments was based on the Indonesia Institute of the Arts Yogyakarta, academic guidebook as shown in Table 1.

The data which gathered from student scores were completed by interviews with the student and instructor. Student and instructor interviews aimed to check whether the score of student's works obtained was true of student learning outcomes using Sibelius or not. 
Table 1 Indonesia institute of the arts Yogyakarta academic guidebook for student assignment

\begin{tabular}{lcc}
\hline No. & Scores & Values \\
\hline 1 & $91-100$ & Excellent \\
2 & $76-90$ & Good \\
3 & $61-74$ & Average \\
4 & $46-60$ & Poor \\
\hline
\end{tabular}

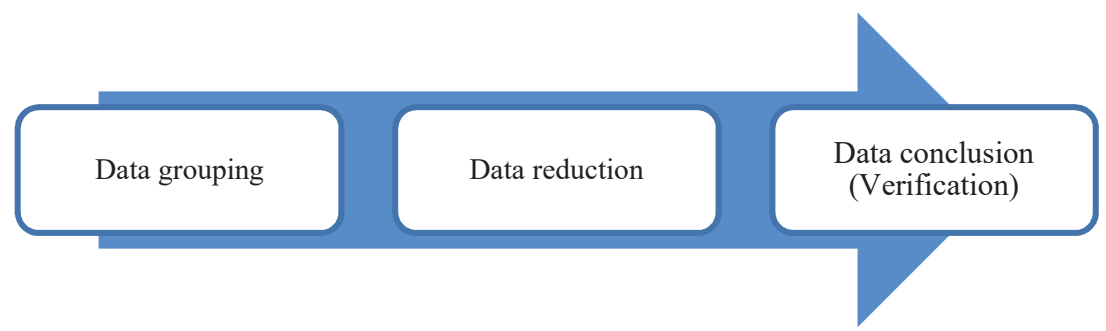

Figure 4 Data analysis.

(4) Reflection: There are some aspects that we need to consider getting the reflection such as analyzing, interpreting, and evaluating the research data. After doing observation, we analyzed, interpreted, and evaluated the work of students whether the use of Sibelius in making counterpoint melody at the Music Department of the Indonesia Institute of the Arts, Yogyakarta, Indonesia, was successful or not. If the use of Sibelius to create counterpoint did not work, the issue was re-evaluated and the process restarted. This procedure was repeated until the issue was resolved.

\subsection{Data Analysis}

The data gathered through observation and interview were evaluated in this study. The data was first separated into significant and unimportant categories. Data that was not relevant to this study was also removed, while data that was relevant was grouped. Second, the linked data were further evaluated, and last, from these data, inferences were developed in order to address research issues and accomplish the study's objectives (see Figure 4).

\subsection{Statistical Analysis}

All statistical analyses were executed using statistical analysis program for window. All variable outcomes were displayed as mean and tested normal 
distribution. The demographic data was examined using a paired t-test or, if suitable, a Wilcoxon rank-sum test. The different outcomes of each CAR cycle were calculated and the result between CAR cycles was compared using a compared $t$-test. The statistical significance was examined as a $p$-value less than 0.05 .

\section{Results}

The student achievement in the first cycle of CAR evaluated according to the Indonesia Institute of the Arts Yogyakarta guidebook showed that most of the students' achievement was good level (Good level: 38.90\%), while the less of students showed the equal number in both Excellent and Average achievement levels (e.g., Excellent level: 30.55\%; Average level: 30.55\%). However, there was no poor achievement level during the first cycle of CAR (see Table 2 and Figure 5).

Table 2 Students' achievement in the first cycle of CAR according to Kemmis and McTaggart's CAR model [9]

\begin{tabular}{lccc}
\hline No. & Level & Number of Students & Percentage \\
\hline 1 & Excellent & 11 & 30.55 \\
2 & Good & 14 & 38.90 \\
3 & Average & 11 & 30.55 \\
4 & Poor & 0 & 0.00 \\
& Total & 36 & 100.00 \\
\hline
\end{tabular}

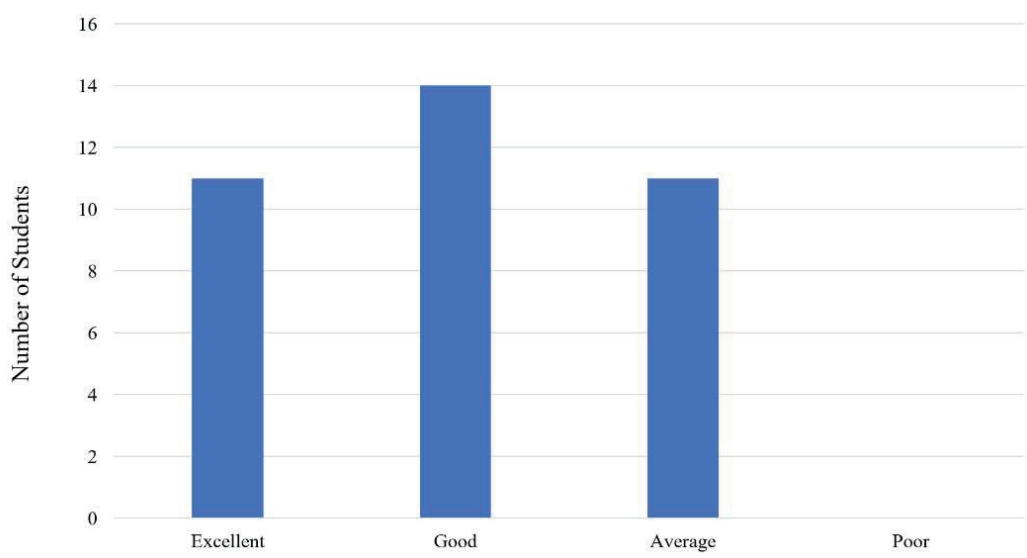

Figure 5 Students' achievement in the first cycle of CAR according to Kemmis and McTaggart's CAR model [9]. 
Table 3 Students' achievement in the second cycle of CAR according to Kemmis and McTaggart's CAR model [9]

\begin{tabular}{lccc}
\hline No. & Values & Number of Students & Percentage \\
\hline 1 & Excellent & 21 & 58.33 \\
2 & Good & 13 & 36.12 \\
3 & Average & 2 & 5.55 \\
4 & Poor & 0 & 0.00 \\
\hline
\end{tabular}

25

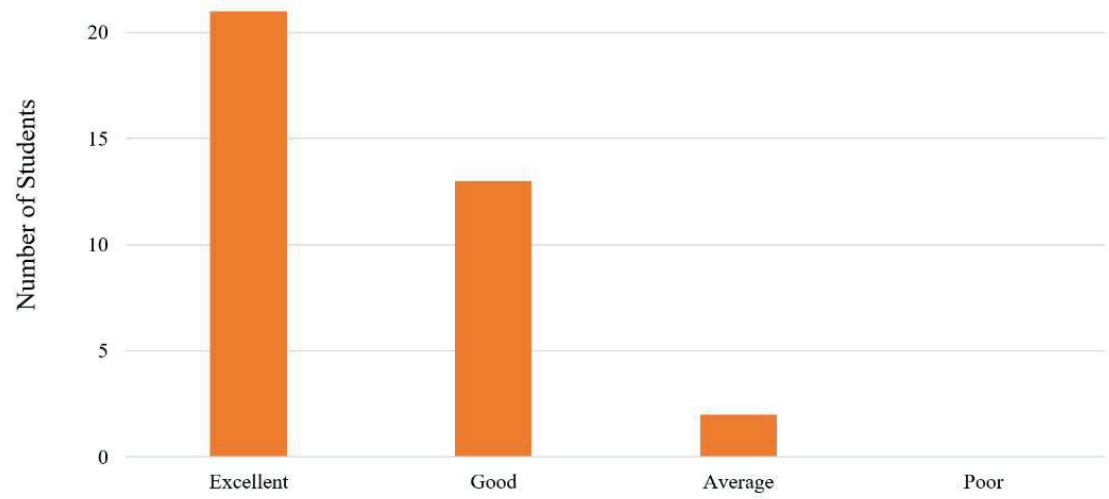

Figure 6 Students' achievement in the second cycle of CAR according to Kemmis and McTaggart's CAR model [9].

During the second cycle of CAR, it was found that most of the students' achievement was moved to the excellent achievement level (Excellent level: 58.33\%) compared to other achievements' levels (e.g., Good level: 36.12\%; Average level: $5.55 \%$ ). Again, there was no poor achievement level during the second cycle of CAR (see Table 3 and Figure 6).

As compared the students' achievements between the first and second cycles of CAR, it was found that the excellent level of students' achievement in the second cycle of CAR was higher than in the first cycle of CAR with statistical significance (First cycle: 30.55 , Second cycle: $58.33, t(71)=1.74$; $p<0.05)$. In contrast to the excellent level of students' achievement, the average level of student's achievement in the first cycle of CAR was higher than the second cycle of CAR with statistical significance (First cycle: 30.55, Second cycle: $5.55, t(71)=1.63 ; p<0.05)$. However, the good level of students' achievement of both first and second cycles of CAR was not statistically significant even though the good level of students' achievement in 


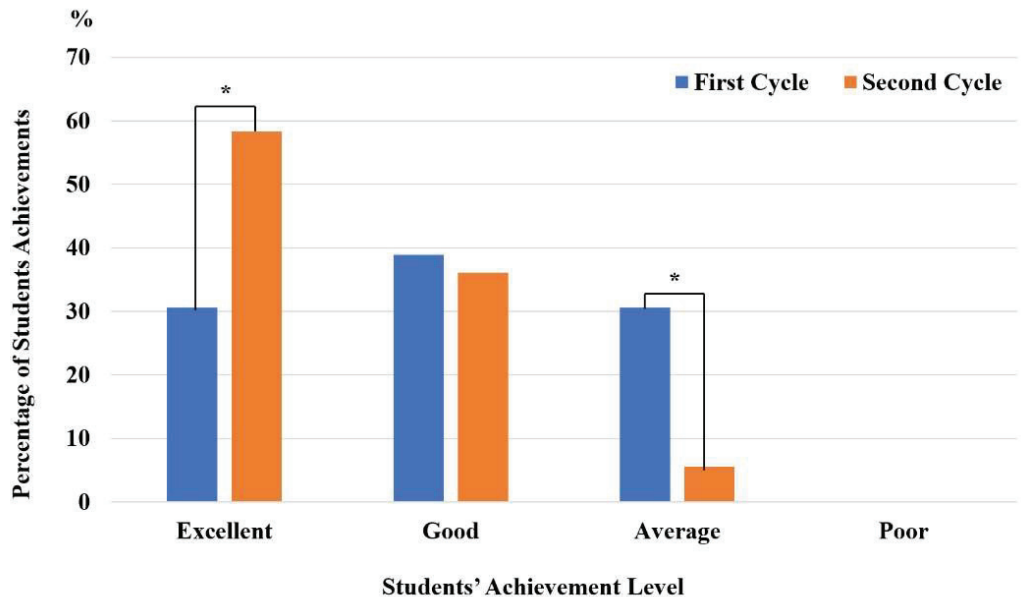

Figure 7 Comparison of students' achievement between the first and second cycles of CAR according to Kemmis and McTaggart's CAR model [9].

the first cycle of CAR was higher than the second cycle of CAR (First cycle: 39.90, Second cycle: $36.12, t(71)=0.96$; n.s.) (see Figure 7). These findings show the improvement of student ability in making two-part invention by using Sibelius.

\section{Discussion}

The present study examined how Sibelius could be used in making twopart invention in learning counterpoint at the Music Department, Indonesia Institute of the Arts Yogyakarta, Indonesia. As compared the students' achievements between the first and second cycles of CAR, it was found that the excellent level of students' achievement in the second cycle of CAR was higher than in the first cycle of CAR. On the other hand, both good and average levels of students' achievement in the first cycle of CAR were higher than the second cycle of CAR. These findings show the improvement of student abilities in making two-part invention by using Sibelius.

\subsection{Music Education and Teaching Program}

Ethnic, linguistic, religious, socioeconomic, and educational inequalities, as well as their interconnections, are increasing the educational problems that come with rising cultural diversity. Teaching education programs in many countries are supposed to educate instructors for this reality and build 
their intercultural competencies. To study intercultural music teacher education, the important case study was built on a network mobilization project between two music teacher programs in previous study. In this previous study, researchers mapped the intercultural abilities required of music educators and offered in two higher institutions for music education in Israel and Finland. A multinational research team conducted 11 interviews and focus groups with music academic staff at Tel Aviv's Levinsky College of Education and Helsinki's Sibelius Academy. Content analysis was used to do an abductive examination of the data. While the educators were able to articulate numerous facets of their own intercultural competence, or lack thereof, the findings suggest that regarding the variety of music education of diverse musical origins, the educators have a lot to learn from one other [11]. The fact that principles of musical organization seem to be consistent across cultures. Music typically contains a number of inherent elements that allow for a listener to more readily perceive and organize it. Methods of musical analysis informed by Lerdahl and Jackendoff, provided a framework for the analysis of harmonic progressions that analyzed harmonic structure and harmonic tension. Several studies on the perception of melodies within a tonal framework revolves around a listener's expectations while listening music. Tonality provides listeners with a way of parsing the musical environments they encounter, using processes derived from physiological, linguistic, cognitive, and cultural constraints and facilitating a perception of centricity, hierarchy, and goal-directedness [12].

The modern symphonic music librarian can use a variety of digital resources to prepare music for performance. Several previous studies examined the most widely used music engraving and music recognition software, picture editing tools, photocopiers, and scanners in symphony libraries today, as well as their applications in music preparation. There was a discussion of the relative efficacy of various software brands, as well as examples of their output. With digital technology, the work of producing correct, clear, and legible printed music for orchestral performers has become considerably faster and easier, and the librarian's possibilities have substantially expanded [13]. Polyphonic music employs harmonic principles to allow numerous melodies to coexist in harmony. Previous studies explained how to produce tonal polyphonic music using a certain algebraic structure. The model was meticulously created using tonal composition concepts from music theory. Additionally, it included considering operands for two-note chords and techniques of melodic conduct. The algebraic model presented in these previous studies builds progressions of chords from variable restrictions, hence ensuring structural 
coherence in automated compositions. This algebraic model has been used to create examples of polyphonic phrases as illustrative results [13, 14]. Learning media serves as a mediator or regulator messages device in learning activities that provide stimulus to the students to understand the material presented by teachers, from abstract concepts into the image of a more concrete, so the student's attitude and behavior will develop [15]. The changes are obtained after students have gained knowledge and new experiences. The use of computer media with Sibelius in learning counterpoint will help students to acquire new knowledge and experiences through the material presented by teachers than if teachers do by way of lectures/verbal approach. Two theories that were used as a framework for our study including the cognitive theory developed by Brunner, and the cone experience theory developed by Edgar Dale [16]. Brunner's cognitive theory states that a person's cognitive development occurs in three stages defined by the way he viewed the environment, such as (a) direct experience phase (eractive), an individual stage to understand the environment by doing activities; (b) pictorial phase (ekonit), an individual stage to see the world through pictures and verbal visualization, such as drawings, paintings, photographs and others; and (c) symbolic stage, is the stage where people have abstract ideas strongly influenced the language and logic of thinking [16]. Because it necessitates a high degree of ideas and imagination, writing songs utilizing an intuitive method frequently reaches a stalemate. One previous study investigated a different way of creativity when writing a song utilizing computer music notation. Sibelius 7 First (henceforth referred to as Sibelius) was the software used for song composition. Over the course of a month, the researchers put their theory to the test by writing a series of songs. In less than a month, Sibelius was able to write nine songs with a variety of melody and rhythm. The songs' melodies were recorded and stored in the computers, where they could be evaluated and updated as needed by the creator, and heard without any need for everyone else to sing. Whenever the music was composed with vocals and checked for quality, it was ready to be played directly to them, students responded positively to the sound and attractiveness of the rhythmic patterns. As a result, it may be inferred that using computer music notation to create quality tunes may boost creativity [17].

\subsection{Application of Technology in Music Learning}

Technology in the globalization era is an integral part of human life. It is true because the globalization concept emerges from the development of 
technology. Globalization is an ideology of cultural, social, and political change that emerges from the development of information and communication technology or known as ICT [18]. The concept of globalization is the world without borders, information liberation, global learning concept, cultural changing concept, and so on. These concepts bring a massive change in the everyday life of a human. Educational technology emphasizes the learning aspects of learners. The main success factor of education is to emphasize how students can learn to identify, develop, organize, and use all kinds of learning resources. Seeing the success factors that have been described, problem-solving is with the use of educational technology by utilizing learning resources. To use the learning resources, the ICT should be done by considering a few things such as (a) the purpose of learning, i.e. appropriateness of the characteristics of learning objectives with the characteristics of learning media will be achieved; (b) effectiveness to determine the most effective media to deliver the content of the subject; (c) the accuracy, which chosen learning media appropriate to the characteristics and abilities of learners (d) availability, the media should be readily available or easy in the procurement; (e) the technical quality has been tested with good results; (f) cost of acquisition. The acquisition costs should fit between the costs incurred with the benefits to be obtained; ( $\mathrm{g}$ ) the flexibility and convenience of the media. The choosing media should give the flexibility, hence the technology can be used in any situation and when not in use it is not harmful; (h) the ability to use the media, of course, no matter how high utility the value media is, it will not provide many benefits for people who are unable to use it [18]. The importance of using technology as a medium of learning in learning counterpoint in the Music Department of Indonesia Institute of the Arts Yogyakarta, Indonesia, was based on the opinion of Webster [19] which states that whatever one's opinion on the importance of technology in the music experience, there's no disputing that computers, keyboards, MP3 players, CDs and other digital devices have never existed in the lives of today's students [19]. The computer is thus an ideal teaching tool in teaching music, mainly by using computer software that is user adjustable to the learning objectives.

Innovative instructional courses that can be taken on their own have long struggled to connect preservice to reality difficulties of using technologies for the purpose of teaching and learning. Despite the fact that many studies have been conducted on the benefits of provider in education, only a few have been conducted in stand-alone educational technology courses. Jia and colleagues examined the benefits and limitations of a learning through service initiative 
that connected teaching and learning educators to real-world technology integration difficulties in K-12 classrooms. A total of 54 undergraduates preservice instructors participated in this analytic case study. They were asked to provide feedback on their technology integration learning through a weekly troubles and reflections surveys. Semi-structured interviews were used to document the most relevant aspects of educators' experiences during in the service program. Educators praised the validity of the service-learning initiative since it allowed them to practice their teaching skills including (a) apply their knowledge and skills in technology integration to reality problems and (b) look into teaching resources and ideas in their topic areas. The challenges that preservice educators face is also discussed. Service-learning can help students have a more realistic learning experience by combining technology with teaching subject. The most effective educator assistance was project orientation and feedback on appropriate technological options [20]. The rapid progress of knowledge technology and digital technology has helped to expand classroom teaching approaches and improve teaching effectiveness. One previous study conducted a theoretical study of urbanrural distance education and built a synchronized urban-rural environment distanced education model based on online digital technology to evaluate the effects of novel English classroom instruction in rural elementary and secondary schools. It gave a thorough design of the urban-rural distance learning that was synchronous with learning process based on the online computer technology, utilizing a particular teaching example to explore and evaluate the effects of urban-rural synchronous distance teaching. This teaching approach has the potential to increase the impact of English classroom instruction in urban-rural primary and secondary schools, and also enable urban-rural integrated teaching and improve English classroom instruction forms [21].

To understand the future educational paradigm, Shubina and Kulakli studied at creativity and pervasive learning in 2019. This previous study was conducted using relevant previous studies and reflective analysis on sub-contexts including creativity, educational development, pedagogical techniques, significant determinants behind creative development, and technology-learning system effects. In educational processes, a variety of difficulties can function as a facilitator or an obstacle to the development of creativity. Technology in education gives various options for creativity development, including support for increasing intrinsic motivation and self-regulation, as well as enhancing curiosity and developing some abilities to improve students' cognitive processes and engagement. In the educational paradigm, the Shubina and Kulakli 
endeavored to explore all of the benefits, obstacles, and risks associated with improving creativity with the use of technology. In order to answer the main research issue, many studies have been analyzed: How a technologyrich classroom environment might help students be more stimulated and increase their creativity [22]. The angklung is one of the traditional musical instruments that Indonesian elementary school students are expected to learn to play (a bamboo musical instrument). Angklung, on the other hand, is a type of group musical instrument, students may have difficulties playing it because it requires collaboration. Thus, Julia et al. created a technologyenhanced touch angklung and used it in the classroom to simplify the process of learning to play angklung. The touch angklung was created by combining a number of computer software and hardware. Sibelius, Kontakt, Sound Forge Audio Studio, and Scratch are the utilized programs. A kit called "MakeyMakey" (MMK) was also applied in this previous study. In order to create a touch angklung, it was necessary to sample the sounds of angklung, create sound buttons on a computer, rebuild the angklung, and combine the touch and MMK angklung. In two schools with a total of 30 students, the touch angklung was introduced into the classroom. Each student took part in a survey to find out how learning to play conventional musical instruments with the touch angklung affected their outcomes. Teachers and researchers conducted their own observations and investigations. The students were very motivated to play touch angklung, according to the findings. They were able to quickly write songs based on the melodies they had memorized. Finally, students were more interested in studying traditional musical instruments when they were coupled with technology [23]. It is possible that simply displaying notations isn't enough to teach Angklung composing. In order to learn songs with new arrangements more readily, learners must comprehend the Angklung composition tones in addition to the notation presentation. One previous study examined a method for creating and used Angklung composition training materials with the help of computer technology, including Sibelius, which is a music notation program, and Kontakt, which was a virtual studio. Computational tools were utilized to examine the Angklung composition production process. The analysis involved the Sibelius and Kontakt integration process. Following the invention of the sound quality test of Angklung compositions, a survey technique was used on 54 students enrolled in a primary school teacher. The results showed that Sibelius and Kontakt worked together to create natural, clean, and clear Angklung music compositions. The majority of students believed the Angklung sound recordings were genuine. The students were ecstatic to learn Angklung on the computer. 
When it comes to Angklung composition teaching tools, combining music notation software with sound sample-based instruments could be intriguing to students [24]. Furthermore, one more previous study examined the positive link between the associated technique and student attitudes, with the conclusion that the correlation could be improved by employing more appealing and high-quality content created for computer-assisted instruction. In this previous study, Anil et al. conducted a meta-analysis to determine the effect of computer-aided education on students' perceptions, establishing how much the impact size generated by aggregating the effect sizes of multiple studies varies depending on educational level, course content, and application time. There were 32 research articles among 621 publications in national and international journals between 2005 and 2015 that met the criteria for inclusion. The data was analyzed using MetaWin 2.0 and Comprehensive Meta-Analysis. Computer-supported schooling demonstrated a moderate, positive, and significant $(\mathrm{ES}=0.449)$ effect on attitude ratings, according to the random effects model [25].

Due to attentional limits, concurrent speech streams might be difficult to absorb. Several musical streams are handled swiftly. In terms of coherence, musical and inputs like speech that do not depend on the integration of several streams for comprehension may differ dramatically. When listening to several lines of music at the same time, the melodic arranging between melodies in a piece may work as a cognitive scaffold to help fight attentional constraints. A prior study investigated at physiological indices associated with perceiving organized versus unorganized music in order to determine how listeners react to multi-voiced music. Because of the consistency offered by harmonic progression across diverse musical lines, a lack of direction would result in continuous tunes being heard as different streams. In a coherent presence of music with flute duets, musicians focused on melodies, those duets, however, were manipulated to lose coherence between the sections in a Jumbled music situation. In this previous study, a tone probe was used to gather auditoryevoked brain potentials. The study focused on the N100 signal, which is produced primarily in the auditory system and is larger for attended stimuli than for ignored stimuli. The findings imply that individuals did not prefer one line over another when listening to coherent melody, according to the data, instead perceptually integrating the streams. The consequences of the jumbled music demonstrate that participants concentrated on one line while ignoring the other, discarding their integration. The concept that musical order enhances attention in multi-voiced audio comprehension is supported by these earlier findings [26]. 
Therefore, the idea of using technology in learning is reinforced by a theory of cone experiences [16]. It classified learning experiences ranging from concrete to abstract things. The experiences here are called the cone of experience. According to the cone of experience, the learning will affect the learning experience, the more abstract treatment of learning for instance with lectures that use symbols, learn to read, respectively. If the learning experience gained is not too significant, increasingly using the medium that directed the real activities (performance) and then the learning experience will be gained to the maximum. Learning media also has an important role in improving the information that we remember which was $70 \%$ compared to the rehabilitated and reconstructed by the lecture method of learning by $20 \%$ [16]. The learning success measured by the level of students' learning experiences gained in learning depends on the treatment. The theory consists of 12 classification learning media which is often used instructional: (a) Direct experience and aims: This experience gained by the student when dealing directly with the objects, events, or the actual object; (b) Experience imitation: This experience obtained by students through objects or events that imitations; (c) Experience through dramatization: The experience gained in the form of various movements of drama that performed on stage and in the open air; (d) Demonstration: The experience gained through the examples or the show of a process; (e) Experience through field trips: The experience gained by getting students to the outside object of the classroom with the intent of enriching and expanding students' experience; (f) Experience through the exhibition: The experience gained through performing the work of students; (g) Experience through television: The experience gained through the educational program that aired on television; (h) Experience through live images or movies; (i) Experience over the radio: The experience gained through radio broadcasts in the form of lectures, interviews, skits, and so on; (j) Experience through pictures: The experience gained from everything that the experience obtained from everything that manifests visibly as a two-dimensional outpouring of emotions and thoughts; (k) Experience through visual symbol: The experience gained through visual symbols; and (l) Experience with the symbol of the word: It is gained from books and reading materials [16]. However, the basis of the experience of this cone is to measure the level of abstraction for the reception of learning content or messages using direct experience, in line with the increasingly consolidated these conceptions, the function of learning media not only as tools but also as a conveyor of information or a learning message to students which will solve the barriers in communication, physical limitations in the classroom, 
students' passivity and also unify their observations. Thus, technology that is used as a learning media must be chosen the most suitable for students [15]. The teacher has the full obligation to choose what kind of technology will be used as a learning medium. It means that the technology used is familiar to students and can be used easily. This is because technology does not become a new problem in learning, but is a tool that can facilitate student work. In our study, Sibelius is a tool that students are familiar with. They know the features of Sibelius. The use of learning media that is familiar to students makes counterpoint learning more efficient and effective. Although Sibelius is a software to write music notation, but it has very useful features that can be used for learning purposes, in this case, it is a feature for writing notations and listening to written musical notations. Music notation writing software such as Sibelius helps provide mental representations, in our study is a counterpoint melody and organizes music notation information in an effective way for learning. Moreover, Sibelius helps provide a mental representation of the written notation to the sound that is heard [27]. The representation of musical notation and sound results in more effective music learning (counterpoint). Music notation writing software would reduce cognitive loan. It means that if making melody counterpoints on stave paper it will use a large cognitive loan, but by using this software, the large cognitive load can be reduced by representing music notation in symbols [28].

\subsection{Software in Music Education}

The variety of pedagogical concepts and solutions gathered around what has come to be known as counterpoint in music education does not negate a common problem that most people face: the usefulness of a well-defined reference system is harmed by its lack of clarity. Many of the most frequent teaching methodologies are radically incompatible with the musical idea of a period, therefore defining a reference repertoire isn't always enough to address this inconsistency. It is vital to critically examine the most widely used treatises in light of their clarity in describing the approach of the musical systems used; of each referential specificity within the modal and tonal systems. Similarly, the teaching strategy, as well as treatises that do not use this paradigm, require a critical reconsideration. At this point, Bonis et al. elaborated on an idea proposed by Arnold Schoenberg to distinguish homophonic and polyphonic thinking in tonal music, revealing ideas on the distinctiveness of melodic and contrapuntal thinking in modal music. As a result, a critical conversation about the functions and effectiveness of a pedagogical proposal 
of this type in music education today was feasible [29]. The question of the link with its environment is equally important in Uexküll's, Goldstein's, and Canguilhem's ideas. In this previous study, a "counterpoint" between both theories is formed in an attempt to determine where the "melodies" are concordant and where they are discordant. Uexküll's theory founded the concept of conformance to a plan, which enables him to account for the congruence and complete adaptation. According to Goldstein and Canguilhem, the interaction between an organism and its environment is more like an issue in which the organism must constantly construct norms to maintain a productive relationship with its environment in order to retain its state of health. The identification of different conceptual frameworks allows the emphasis to be placed on the fact that each theory is based on distinct assumptions about teleology and sense in organisms, as well as specific definitions of the term "life" in general. Finally, the notion that creatures and their environs originate from a unique and common source, a principle or a design that must possess all of life's creative features, is deemed to prevail [30]. In Western music theory, counterpoint is a crucial idea. There has been considerable interest in adding counterpoint into the composition of Chinese folk music throughout the last century. Researchers presented FolkDuet, an online countermelody generating system based on reinforcement learning for Chinese folk melodies, in this previous study. FolkDuet employs two outof-domain reward models, notably Bach chorales and monophonic Chinese folk songs, because there isn't any information about Chinese folk duets. To model melodic patterns, on monophonic Chinese folk songs, a style reward model was trained whereas a reward model for interaction is trained on duets constructed from the outer portions of Bach chorales to reflect counterpoint interaction. Chinese folk countermelodies have been taught to FolkDuet's generator, such that it can generate countermelodies that have both rewards. The entire generation process occurs online, allowing for improvisation between a human and a machine in real time. Experiments show that the suggested algorithm outperforms baseline algorithms in terms of subjective and objective outcomes [31]. Moreover, Curreri has shown how avant-garde musical interventions helped eight paediatric patients in a small 12-bed acute mental hospital. In the mental unit, the music therapist had to deal with two big challenges. First, regardless of their ages, cultures, or ailments, the hospital administration aggressively encouraged all eight patients participated in music therapy sessions at the same time. Second, patients commonly lost focus, concentration, and attention when music therapy approaches emphasized tonal harmonies, melodies, and counterpoint, in addition to regular 
rhythms or time signatures, making it impossible to concentrate on basic skills such as following orders and building secure boundaries, or to examine feelings and emotions. As an alternative to traditional diatonic therapy, the music therapist devised three unique sound-based approaches, using avantgarde composers as a source of inspiration including Pauline Oliveros, John Cage, and Luigi Nono. Not only did the eight patients benefit from the unique musical treatments, but they also improved their attentional abilities. It also aided in the development of (a) a strong therapist-patient relationship based on mutual trust, (b) empower individuals to create, explore, and discover in a therapeutic context, (c) nonverbally expose unexpressed feelings, and (d) introduce new individuals to their unique musical experiences [32].

Software was used in music education to support learning and enhance the learning environment during the learning process. In our study, Sibelius was used as a learning/teaching tool for counterpoint course. It allowed students to experience being actively involved in making counterpoint compositions. Students who actively participated in learning found it simpler to memorize, absorb, and comprehend information. As explained in the cone theory that direct active participation in the learning process via learning media would increase students' understanding and memory retention by $90 \%$. Similar to previous study done by Mead and his colleagues in 2019, Mead et al. published a case study presenting a continuous curriculum initiative since 2009, analyzing "Scratch 3" in order to improve the sequencing abilities of Lambeth College's (South London) students with learning disabilities (LLDD). A 12year-old secondary school student created Scratch 3 block coding tutorials with Sibelius music program for students at the higher learning institution. Students have benefited much from this series' most demanding teaching and learning activity [33]. In addition, Sibelius program was utilized in our study as a teaching tool to help students understand and produce melody counterpoints. The choice of Sibelius was predicated on the fact that both teachers and students were familiar with the software. Sibelius was used in this case as an example of music notation software in music instruction. Additionally, the findings of this previous study confirm that other music notation software, such as Finale, NoteFlight, Notation 6, or MuseScore [34], that has many of the same capabilities as Sibelius, can be utilized for music education. However, ensure that the software chosen for learning has been mastered by teachers and students, so that no new problems arise during the learning process: students are unfamiliar with the software used for learning.

According to our findings, we come to final conceptualization that in learning counterpoint using Sibelius software, students acquire cognitive 
experience obtained through direct experience that is the experience of using the software in making counterpoint melodies, which is then continued by looking at images (musical notation) and then at the symbolic stage, the musical notation provides abstract ideas that ultimately affect the logic of student thinking, to make a melody counterpoint musically. This is as Dale says in his cone of experience theory which states that individuals obtain the experience, they remember the most with the largest percentage $(90 \%)$ when the individual has a learning experience by doing the real thing. In counterpoint learning using Sibelius software, students do the real thing, i.e. they do their exercises to create counterpoint melodies. The accumulation of cognitive experience and real experience meet by students makes Sibelius software a very useful tool for students in creating counterpoint melodies. The learning experience obtained by students with Sibelius software is also very determined by teachers. In addition to Sibelius as a learning tool to make a counterpoint, the learning process makes counterpoint also using student experience-based learning. This is based on Dale's experience cone which is to measures the level of abstraction in the acceptance of learning content or messages using hands-on experience. In line with the conception, the function of learning media is not only as a tool but also as a carrier of information or learning messages to students who will overcome obstacles in communicating, physical limitations in the classroom, student passivity, and also unite their observations. The teacher is the main determinant in determining what kind of learning technology is in accordance with the learning they taught, so that the technology used provides benefits for the achievement of learning objectives. Sibelius is an example of using technology as a learning tool. Of course, the success of students in using Sibelius in counterpoint learning is also supported by a supportive learning atmosphere and high learning motivation from students.

\section{Conclusion}

Using Sibelius in making a two-part invention in counterpoint at Music Department of the Indonesia Institute of the Arts, Yogyakarta, Indonesia, was done successfully. The results provided the advantages for students in doing two-part invention and problem-solving in learning counterpoint. Sibelius supported learning counterpoint more efficient and effective. The improvement of student's ability in making two-part inventions was the significant result of this study, and it made the goal of the counterpoint's course content achieved, that was students can make two-part inventions. 
The results obtained provide a conclusion that the use of Sibelius in counterpoint learning is a tool to help students understand learning material and as a means to train students' skills in making counterpoint melody. It also shows that technology (Sibelius) used in education is used as a learning tool. As in cognitive theory (Brunner) and The Cone Experience Theory (Dale) which states that individuals gain cognitive experience derived from direct experience, pictorial, symbolic stage.

\section{Acknowledgements}

Graduate School at the Indonesian Institute of the Arts, Yogyakarta, Indonesia, contributed to this research. We would like to express our gratitude to all of the students that took part in this study. The authors would like to thank Ovan Bugus Jatima for coordinating this study. The authors would like to express their gratitude to the Indonesia Institute of Arts in Yogyakarta, Indonesia, and the Mae Fah Luang University School of Anti-Aging and Regenerative Medicine in Thailand.

\section{Contributors}

Conceptualized, designed and conducted the study: Oriana Tio Parahita Nainggolan, Ayu Niza Machfazia, and Phakkharawat Sittiprapaporn; Collected data: Oriana Tio Parahita Nainggolan, and Ayu Niza Machfazia; Draft manuscript: Oriana Tio Parahita Nainggolan, Ayu Niza Machfazia, and Phakkharawat Sittiprapaporn; Supervised the study: Fortunata Tyasrinestu; Investigated the study: Djohan; Statistically analysed and interpreted the data: Phakkharawat Sittiprapaporn; Critical revision of the manuscript and project administration: Phakkharawat Sittiprapaporn. The published version of the manuscript has been read and approved by all authors. Phakkharawat Sittiprapaporn is corresponding author.

\section{References}

[1] Horton, C., Byrne, D. A., and Ritchey, L. (2020). Harmony through melody: The interaction of melody, counterpoint, and harmony in Western music. Rowman \& Littlefield Publishers.

[2] G.E. Corazza, S. Agnoli, and S. Martello, "Counterpoint as a principle of creativity: Extracting divergent modifiers from 'The Art of Fugue' by Johann Sebastian Bach," Musica Docta, vol. 4, no. 2, pp. 93-105, 2014. 
[3] H. Norden, "Fundamental Counterpoint," Boston: Crescendo Publishing Company, 1969.

[4] K. Jeppesen, "Counterpoint: the polyphonic vocal style of the sixteenth century," Courier Corporation, 2013.

[5] D. Herremans, and K. Sörensen, "Composing fifth species counterpoint music with a variable neighborhood search algorithm," Expert systems with applications, vol. 40, no. 16, pp. 6427-6437, 2013.

[6] M. Deganutti, "The Counterpoint Music of the Exile in Fulvio Tomizza's La ragazza di Petrovia," Romance Studies, vol. 34, no. 2, pp. 114-124, 2016.

[7] S. Watson, "Using technology to unlock musical creativity," OUP USA, 2011.

[8] S. Nart, "Music software in the technology integrated music education," Turkish Online Journal of Educational Technology-TOJET, vol. 15, no. 2, pp. 78-84, 2016.

[9] S. Kemmis, and R. McTaggart, "The Action research Reader," 3rd ed., Victoria: Deakin University Press, 1988.

[10] G.I. Susman, "Action Research: A Socio Technical Systems Perspective," Tahun: Sage Publications, Tahun, pp. 95-113, 1983.

[11] L. Miettinen, C. Gluschankof, S. Karlsen, and H. Westerlund, "Initiating mobilizing networks: Mapping intercultural competences in two music teacher programmes in Israel and Finland," vol. 40, no. 1, pp. 67-88, 2018.

[12] D. Shanahan, "Musical Structure: Tonality, Melody, Harmonicity, and Counterpoint, Routledge Companion to Music Cognition," Routledge, 2017.

[13] M. Naughtin, "Digital Music Preparation in the Modern Orchestral Library, in D. Baker (ed.), Wendy Evans, The End of Wisdom?, Chandos Publishing, pp. 87-103, 2017.

[14] E.G.G. de Paz, M. Quintero-Flores, and X. Quiñones-Solís, "On the Construction of a Specific Algebra for Composing Tonal Counterpoint. In: J. Martínez-Trinidad, J. Carrasco-Ochoa, J. Olvera-López, and S. Sarkar (eds), Pattern Recognition. MCPR 2018. Lecture Notes in Computer Science, 10880, Springer: Cham, 2018.

[15] J. Črčinovič Rozman, and B. Kovačič, "Use of learning media and technology by preparation and realization of music lessons," Informatologia, vol. 41, no. 3, pp. 175-182, 2008.

[16] D. Dale, "Audio-Visual Methods in Teaching," New York: Dryden Press, 1946. 
[17] J. Julia, P.D. Iswara, and T. Supriyadi, "Song creation by using computer music notation," IOP Conf. Series: Materials Science and Engineering, vol. 434, no. 012055, 2018.

[18] A. Rahim, and A. Rashid, "Profesionalisme Keguruan Prospek dan Cabaran," Kuala Lumpur: Dewa Bahasa dan Pustaka, 2005.

[19] P.R. Webster, "Computer-based technology and music Teaching and Learning," New York: Schirmer Books, 2001.

[20] X. Jia, J. Jung, and A. Ottenbreit-Leftwich, "Learning Technology Integration from a Service-Learning Project: Connecting Preservice Teachers to Real-World Problems," Journal of Experiential Education, vol. 41, no. 3, pp. 261-276, 2018.

[21] Y. Gong, "Innovative English Classroom Teaching Based on Online Computer Technology in Rural Middle and Primary Schools," International Journal of Emerging Technologies in Learning, vol. 13, no. 10, pp. 1-14, 2018.

[22] I. Shubina, and A. Kulakli, "Pervasive Learning and Technology Usage for Creativity Development in Education," International Journal of Emerging Technologies in Learning, vol. 14, no. 1, pp. 95-109, 2019.

[23] J. Julia, T. Supriyadi, and P.D. Iswara, "The development of angklung composition teaching materials using Music Notation Software with virtual studio technology integration," vol. 1157, no. 042005, 2019.

[24] J. Julia, P.D. Iswara, and T. Supriyadi, "Redesigning and Implementing Traditional Musical Instrument in Integrated Technology Classroom," International Journal of Emerging Technologies in Learning, vol. 14, no. 10, pp. 75-87, 2019.

[25] Ö. Anıl, V. Batdı, and H. Küçüközer, "The effect of computer-supported education on student attitudes: A meta-analytical comparison for the period 2005-2015," Educational Sciences: Theory \& Practice, vol. 18, pp. 5-22, 2018.

[26] K.C. Barrett, R. Ashley, D.L. Strait, E. Skoe, C.J. Limb, and N. Kraus, "Multi-Voiced Music Bypasses Attentional Limitations in the Brain," Front. Neurosci., vol. 15, no. 588914, 2021.

[27] M.D.M. Galera Núñez, J. Tejada Giménez, and M.E. Trigo Sánchez, "Music notation software as a means to facilitate the study of singing musical scores," Electronic Journal of Research in Educational Psychology, vol. 11, no. 1, pp. 215-238, 2013.

[28] A. Comas-Quinn, R. Mardomingo, and C. Valentine, "Mobile blogs in language learning: Making the most of informal and situated learning opportunities," ReCALL, 21(1), vol. 21, no. 1, pp. 96-112, 2009. 
[29] de B. Mauricio, "Por um desemaranhamento do contraponto," Opus, vol. 24, no. 2, pp. 1-21, 2018.

[30] A. Ostachuk, and B. Jakob von, "The organism and its Umwelt A counterpoint between the theories of Uexküll, Goldstein, and Canguilhem in Uexküll and Philosophy," New York: Routledge, 2019.

[31] N. Jiang, S. Jin, Z. Duan, and C. Zhang, "When counterpoint meets Chinese folk melodies, in Advances in Neural Information Processing Systems, vol. 2020-December 2020, 3th Conference on Neural Information Processing Systems, NeurIPS 2020, Virtual, Online, 6 December 2020-12 December 2020, 169463, 2020.

[32] E. Curreri, "Nurturing Attentional Skills in Acute Paediatric Psychiatry Through Avant-Garde Musical Interventions," Music Therapy Perspectives, vol. 36, no. 2, pp. 243-256, 2018.

[33] L. Mead, L. Williams, and B. Mead, "A Pilot Teaching Project, "Keeping Safe", Exploring the Use of "Scratch 3" Computer Coding Files and Computer-Generated Music Files Created in "Sibelius", to Support Young Adults with Language Learning Difficulties and Disabilities at Lambeth College, in South London. In: Tatnall A., Mavengere N. (eds) Sustainable ICT, Education and Learning, SUZA, IFIP Advances in Information and Communication Technology, vol. 564. Springer, Cham, 2019.

[34] A.D. Villani Jr, A. D. "An appraisal of the use of computer music notation software among selected high school music teachers," Doctoral dissertation, Boston University, 2014.

\section{Biographies}

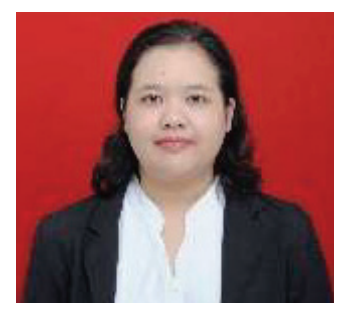

Oriana Tio Parahita Nainggolan received Bachelor and Master's degree of Music from Music Department, Faculty of Performing Arts, Graduate School of Institut Seni Indonesia Yogyakarta, Indonesia. She is currently a researcher at Music Education Department, Faculty of Performing Arts, 
Indonesia Institute of the Arts, Yogyakarta, Indonesia. Her research interest is Performing Arts and Music.

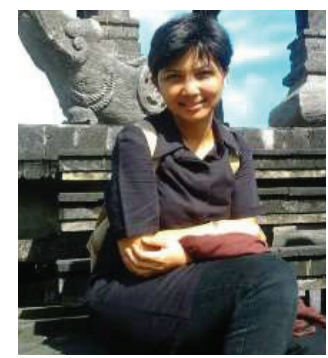

Ayu Niza Machfazia received Bachelor's degree of Music from Music Department, Faculty of Performing Arts, Undergraduate School of Indonesia Institute of the Arts Yogyakarta, Yogyakarta, Indonesia. She received master's degree of Technical and Vocational Education from Graduate School of Yogyakarta State University, Yogyakarta, Indonesia. She is currently a researcher at Music Department, Faculty of Languages and Arts, Yogyakarta State University, Yogyakarta, Indonesia. Her research interest is Performing Arts and Music.

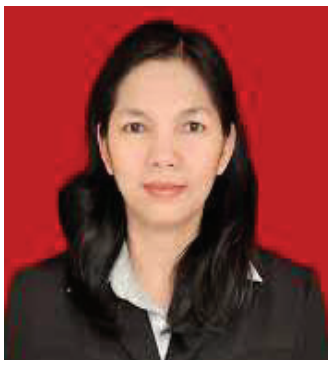

Fortunata Tyasrinestu received Bachelor's degree in Music from the Indonesian Institute of the Arts, Yogyakarta, and Indonesian Literature from Universitas Gadjah Mada Yogyakarta, Masters' degree in Psychology from Gadjah Mada University, and Doctoral degree in Social Sciences from Gadjah Mada University. She is Associate Professor at Music Department, Faculty of Performing Arts, Indonesia Institute of the Arts, Yogyakarta, Indonesia. She is currently a Director at Graduate School of Indonesia Institute of the 
Arts Yogyakarta, Yogyakarta, Indonesia. Her research interest includes Music Education and Social Sciences.

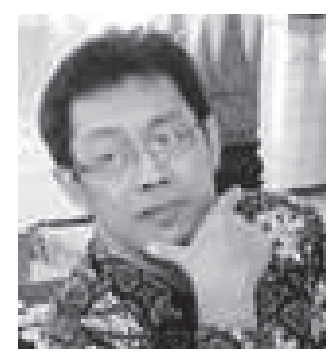

Djohan received bachelor's degree in Music from Indonesia Institute of the Art, Yogyakarta. Masters' degree in Psychology from Gadjah Mada University, and Doctoral degree in Psychology from Gadjah Mada University. $\mathrm{He}$ is currently a Professor at Music Performance Department, Faculty of Performing Arts, Indonesia Institute of the Arts, Yogyakarta, Indonesia. His research interest is Neuromusicology and Cognitive Ethnomusicology.

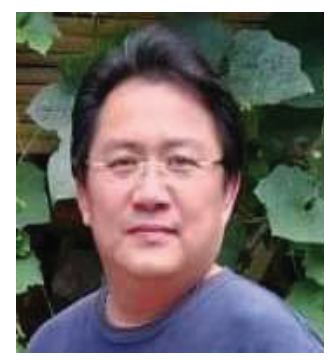

Phakkharawat Sittiprapaporn received Bachelor of Arts (Second Class Hons.) in English from Srinakharinwirot University, Thailand, Master of Arts in Linguistics, Institute of Language and Cultural for Research and Development from Mahidol University, Thailand, and Ph.D. in Neurosciences, Neuro-Behavioural Biology Center, Institute of Science and Technology for Research and Development Mahidol University, Thailand. He is currently a Head of Brain Science and Engineering Innovation Research Group, Mae Fah Luang University, and Neuropsychological Research Laboratory, as well as a lecturer at Department of Anti-Aging and Regenerative Science School 
of Anti-Aging and Regenerative Medicine, Mae Fah Luang University, Bangkok, Thailand. His research interests are cognitive psychology, cognitive neurosciences, cerebral mechanisms in perception and cognition, brain mechanism of music and language perception and cognition, and neurobiology of learning and memory. 
